\title{
Comparative study of two commercially pure titanium casting methods
}

\author{
Renata Cristina Silveira RODRIGUES ${ }^{1}$, Adriana Claudia Lapria FARIA ${ }^{2}$, lara Augusta ORSI $^{3}$, \\ Maria da Gloria Chiarello de MATTOS ${ }^{4}$, Ana Paula MACEDO ${ }^{5}$, Ricardo Faria RIBEIRO 4
}

1- DDS, MSc, PhD, Assistant Professor, Department of Dental Materials and Prosthodontics, Ribeirão Preto Dental School, University of São Paulo, Ribeirão
Preto, SP, Brazil.
2- DDS, MSc, Graduate student, Ribeirão Preto Dental School, University of São Paulo, Ribeirão Preto, SP, Brazil.
3- DDS, MSc, PhD, Associate Professor, Department of Dental Materials and Prosthodontics, Ribeirão Preto Dental School, University of São Paulo, Ribeirão
Preto, SP, Brazil.
4- DDS, MSc, PhD, Full Professor, Department of Dental Materials and Prosthodontics, Ribeirão Preto Dental School, University of São Paulo, Ribeirão
Preto, SP, Brazil.
5- Electrical Engineer, Department of Dental Materials and Prosthodontics, Ribeirão Preto Dental School, University of São Paulo, Ribeirão Preto, SP, Brazil.

Corresponding address: Dra. Renata Cristina Silveira Rodrigues - Departamento de Materiais Dentários e Prótese - Faculdade de Odontologia de Ribeirão Preto, Universidade de São Paulo - Av. do Café, s/n - Monte Alegre - Ribeirão Preto, SP - Brasil - 14040-904 - Phone: +55 (16) $3602-4005$ - Fax: +55 (16) 3633-0999 - e-mail: renata@forp.usp.br

Received: March 5, 2009 - Modification: September 28, 2009 - Accepted: February 16, 2010

\section{ABSTRACT}

T he interest in using titanium to fabricate removable partial denture (RPD) frameworks has increased, but there are few studies evaluating the effects of casting methods on clasp behavior. Objective: This study compared the occurrence of porosities and the retentive force of commercially pure titanium ( $\mathrm{CP} \mathrm{Ti}$ ) and cobalt-chromium ( $\mathrm{Co}-\mathrm{Cr}$ ) removable partial denture circumferential clasps cast by induction/centrifugation and plasma/vacuum-pressure. Material and Methods: 72 frameworks were cast from $\mathrm{CP} \mathrm{Ti}$ $(n=36)$ and Co-Cr alloy $(n=36$; control group). For each material, 18 frameworks were casted by electromagnetic induction and injected by centrifugation, whereas the other 18 were casted by plasma and injected by vacuum-pressure. For each casting method, three subgroups $(n=6)$ were formed: $0.25 \mathrm{~mm}, 0.50 \mathrm{~mm}$, and $0.75 \mathrm{~mm}$ undercuts. The specimens were radiographed and subjected to an insertion/removal test simulating 5 years of framework use. Data were analyzed by ANOVA and Tukey's to compare materials and cast methods $(\alpha=0.05)$. Results: Three of 18 specimens of the induction/centrifugation group and 9 of 18 specimens of plasma/vacuum-pressure cast presented porosities, but only 1 and 7 specimens, respectively, were rejected for simulation test. For Co-Cr alloy, no defects were found. Comparing the casting methods, statistically significant differences $(p<0.05)$ were observed only for the Co-Cr alloy with $0.25 \mathrm{~mm}$ and $0.50 \mathrm{~mm}$ undercuts. Significant differences were found for the $0.25 \mathrm{~mm}$ and $0.75 \mathrm{~mm}$ undercuts dependent on the material used. For the $0.50 \mathrm{~mm}$ undercut, significant differences were found when the materials were induction casted. Conclusion: Although both casting methods produced satisfactory CP Ti RPD frameworks, the occurrence of porosities was greater in the plasma/vacuum-pressure than in the induction/centrifugation method, the latter resulting in higher clasp rigidity, generating higher retention force values.

Key words: Chromium alloys. Dental casting technique. Materials testing. Removable partial dentures. Titanium.

\section{INTRODUCTION}

Over the past decade, studies have reported the advantages of commercially pure titanium (CP Ti) and its alloys, and have investigated the possibility of its use in the fabrication of removable partial denture (RPD) metal frameworks $2,13,15,16,20$.

Characteristics like low density, high melting temperature and reactivity at high temperatures are factors that increase difficulties in the $\mathrm{CP} \mathrm{Ti}$ casting process, thus limiting its use $8,10,14,17,18,22$. Despite new casting machines for $\mathrm{CP} \mathrm{Ti}$, some technological problems, such as porosity and inadequate mold filling, remains $\mathbf{s}^{5-7,9}$.

Because of metal low density, porosities can be identified in $\mathrm{CP}$ Ti by conventional radiographic 
imaging, permitting to control framework quality ${ }^{4,21}$. This control is extremely important, since voids and pores may affect fatigue resistance of RPD frameworks subjected to repeated load cycles during chewing and to frequent insertion and removal.

There are few studies about the different CP Ti casting methods7,17. Some authors have observed that centrifugation exerts greater force, producing better castability results ${ }^{19,24}$. Others have shown that the type of casting machine does not significantly influence the internal porosity in $\mathrm{CP} \mathrm{Ti}$ castings ${ }^{7}$. The correlation between casting methods and RPD mechanical properties is yet to be studied.

The present study investigated the hypothesis that the casting method (1- electric arc plasma in a vacuum and argon-inert atmosphere with injection of the metal/alloy into the mold by vacuum pressure; and 2- induction in a vacuum and argoninert atmosphere with injection by centrifugation) does not influence the occurrence of porosities and the retentive force of titanium clasps to be used in RPD frameworks. Co-Cr alloy, the material of choice to make these frameworks, was used as control.

\section{MATERIAL AND METHODS}

Three metallic matrices representing a partially edentulous mandibular right hemi-arch segment were made of a Co-Cr alloy (Remanium GM380; Dentaurum, Pforzheim, Germany) to perform the insertion/removal simulation test. Remaining teeth in the hemi-arch segment were: $2^{\text {nd }}$ premolar and $2^{\text {nd }}$ molar; $1^{\text {st }}$ molar was missing. On these matrices, the molar and premolar teeth were modified with a 2.0-mm-deep occlusal rest, distal and mesial, respectively. In addition, mesial and lingual guideplanes were prepared on the molar teeth and distal and lingual guide-planes on the premolar teeth (two-thirds the crown length), to standardize the path of insertion and removal. The matrices presented undercuts corresponding to $0.25 \mathrm{~mm}$, $0.50 \mathrm{~mm}$ and $0.75 \mathrm{~mm}$. The methodology used in the present study was similar to that described by Rodrigues, et al. ${ }^{15,16}(2008,2002)$.

To reproduce the metallic matrices in refractory material, six silicone molds were fabricated (Elite Double; Zhermack S.p.A., Rovigo, Italy) ( $n=2$ for each undercut), on which casts were poured with Rematitan Plus investment (CP Ti) and Castoritsuper C (Co-Cr alloy).

Investment casts were placed on the dental surveyor, following the path of insertion determined by the guide-planes, and prefabricated patterns of circumferential clasps were placed on the casts (Rewax, Renfert GmbH, Hilzingen, Germany). A pin (5.0-mm wide and 60-mm long; Plastifama Ind. e Com. de Plásticos Ltda., São Paulo, SP, Brazil) was positioned on the clasp set, using the surveyor, to fix specimens to the testing machine. The pin was fixed using sculpture wax (Sybron-Kerr, Romulus, MI, USA), which served as feeding sprue for the molten alloy. The molds were completed with the investments described above, according to the material to be used.

Seventy-two specimens were casted from $\mathrm{CP} \mathrm{Ti} \quad(\mathrm{n}=36$; Tritan grade I; Dentaurum, Pforzheim, Germany) and Co- $\mathrm{Cr}$ alloy ( $\mathrm{n}=36$; Magnum H50N, MESA, Brescia, Italy). For each material, 18 specimens were casted by plasma/ vacuum-pressure and the other 18 by induction/ centrifugation, divided into 3 subgroups $(n=6)$, according to undercuts corresponding to $0.25 \mathrm{~mm}$, $0.50 \mathrm{~mm}$ and $0.75 \mathrm{~mm}$.

Plasma/vacuum-pressure castings were made in the Discovery Plasma machine (EDG Equipamentos e Controles Ltda., São Carlos, SP, Brazil), which uses plasma as the means for energy transmission to cast most metals and metallic alloys, such as $\mathrm{CP} \mathrm{Ti}$ and $\mathrm{Co}-\mathrm{Cr}$. The casting unit is formed by two interconnected chambers. The cast metal is injected into the mold by the vacuum-pressure system, in which the mold (ring) is subject to a pressure of $2.0 \mathrm{~kg} / \mathrm{cm}^{2}$ (1471.12 torr) in the upper part and vacuum in the lower part.

The machine used for induction/centrifugation castings was the Neutrodyn Easyti (MANFREDI S.r.l., Torino, Italy), by electromagnetic induction, under a vacuum and argon-inert atmosphere, using a vacuum level of $-0.82 \mathrm{~kg} / \mathrm{cm}^{2}$ (-600 torr) and argon pressure of $0.20 \mathrm{~kg} / \mathrm{cm}^{2}$ (150 torr).

After casting, the specimens were subject to air-particle abrasion with aluminum oxide $100 \mu \mathrm{m}$ (80 psi - $5.62 \mathrm{kgf} / \mathrm{cm}^{2}$ ). Co-Cr specimens were subjected to standardized electrolytic polishing in a VRC apparatus (R.R. Equipamentos para Prótese Dentária Ltda., São Paulo, SP, Brazil), using the electrolytic solution Lustrabem (R.R. Equipamentos para Prótese Dentária Ltda.). For CP Ti specimens, standardized chemical polishing was used, with specimens immersed in Kroll solution ( $10 \mathrm{~mL} \mathrm{HF}$, $30 \mathrm{~mL} \mathrm{HNO}_{3}$ and $50 \mathrm{~mL}$ water) for $1 \mathrm{~min}$.

Before the simulation test, all specimens were radiographically examined to detect possible casting defects that could compromise subsequent use. Radiographic exams were made using a laboratory unit (X-Control; Dentaurum, Ispringen, Germany), set at $70 \mathrm{kV}$ and $8 \mathrm{~mA}$, for a 1.5$\mathrm{s}$ exposure time at $200 \mathrm{~mm}$ from the specimen. Polapan 57 high-speed panchromatic black and white film (Polaroid Corp., Cambridge, USA) was used, with an area of $4 \times 5$ in, self-developed for 20 s. After film development, image fixation fluid was applied. Each test group (alloy/retention level/ casting system), i.e., 6 specimens per film, was radiographed along with a scaled X-ray device for CP Ti x-rays (Dentaurum).

The radiographs were analyzed to evaluate if the specimens could be used or not. It had been established that specimens presenting defects on clasp retentive arms would be discarded and 
replaced.

In order to perform the simulation test, a testing apparatus designed at the Department of Dental Materials and Prosthodontics of the Ribeirão Preto Dental School, University of São Paulo, was used. The apparatus allowed for the insertion of the metallic framework into its terminal position on the $\mathrm{Co}-\mathrm{Cr}$ matrices and its subsequent removal, thus simulating the placement and removal of an RPD.

To analyze the data obtained during the simulation test, intervals corresponding to $0,1 / 2$, $1,2,3,4$, and 5 years were established. A total of 7,205 cycles were performed, representing the simulated insertion and removal of the RPD over 5 years, estimating that the patient would perform four complete cycles per day. The test was performed with 40 cycles/min at a constant speed of $35.79 \mathrm{~mm} / \mathrm{s}^{16}$. The value established for each time interval corresponded to the arithmetic average of 10 consecutive insertion/removal cycles. The force required for each specimen removal was captured and stored using data acquisition software (LabVIEW 5.0.1, National Instruments, Austin, TX, USA).

For the simulation test, using SPSS 12.0 for Windows (SPSS Inc. Chicago, IL, USA), sample error was distributed and showed normal and homogeneous distribution; ANOVA was then performed. Tukey's complementary test was used to compare casting methods for the same material, and the materials casted by the two methods, with the same undercuts. The significance level was set at $5 \%$.

\section{RESULTS}

The radiographs of the $\mathrm{Co}-\mathrm{Cr}$ test specimens did not allow the visualization of defects that would contraindicate the use of such specimens for the insertion/removal simulation test. Three of the $18 \mathrm{CP} \mathrm{Ti}$ specimens casted by induction presented porosities whereas, for the plasma cast group, porosities were detected in nine of the 18 specimens. However, only specimens presenting defects in retention arm clasps were rejected, representing one induction casted specimen $(5.55 \%)$ against seven plasma casted specimens $(38.88 \%)$. Figures 1 and 2 show the retention force values observed in all test conditions.

Comparison between the cast methods by Tukey's post-hoc test revealed that $\mathrm{Co}-\mathrm{Cr}$ alloy specimens presented significant differences $(p<0.05)$ for both $0.25 \mathrm{~mm}$ (I: $30.06 \pm 4.50 \mathrm{~N}$; P: $20.11 \pm 2.90 \mathrm{~N}$ ) and $0.50 \mathrm{~mm}(\mathrm{I}: 30.04 \pm 5.97 \mathrm{~N}$; $P: 22.25 \pm 5.72 \mathrm{~N}$ ), while there were no statistically significant differences ( $p>0.05)$ for $0.75 \mathrm{~mm}$ group (I: $27.79 \pm 7.20 \mathrm{~N}$; P: $31.21 \pm 4.45 \mathrm{~N}$ ). No significant differences $(p>0.05)$ were found between $\mathrm{CP} T \mathrm{Ti}$ specimens casted by induction or plasma in any of the different undercuts evaluated: $0.25 \mathrm{~mm}$ (I: $14.57 \pm 2.06 \mathrm{~N} ; \mathrm{P}: 14.81 \pm 2.94 \mathrm{~N}), 0.50 \mathrm{~mm}(\mathrm{I}:$ $19.65 \pm 1.33 \mathrm{~N} ; \mathrm{P}: 15.15 \pm 3.12 \mathrm{~N})$, and $0.75 \mathrm{~mm}$ (I: $15.85 \pm 0.921 \mathrm{~N}$; P: $16.08 \pm 2.50 \mathrm{~N}$ ).

$\mathrm{Co}-\mathrm{Cr}$ and $\mathrm{CP} \mathrm{Ti}$ was compared in the same undercut and casting method, and significant differences were observed for $0.25 \mathrm{~mm}(p<0.0001)$ and $0.75 \mathrm{~mm}(p<0.0001)$ undercuts, whereas for the $0.50 \mathrm{~mm}$ undercut, only $\mathrm{Co}-\mathrm{Cr}$ specimens cast by induction was significantly different $(p<0.0001)$.

Regarding the behavior of the metallic structures over time, it was observed that the Co-Cr alloy

\section{$\mathrm{Co}-\mathrm{Cr}$}

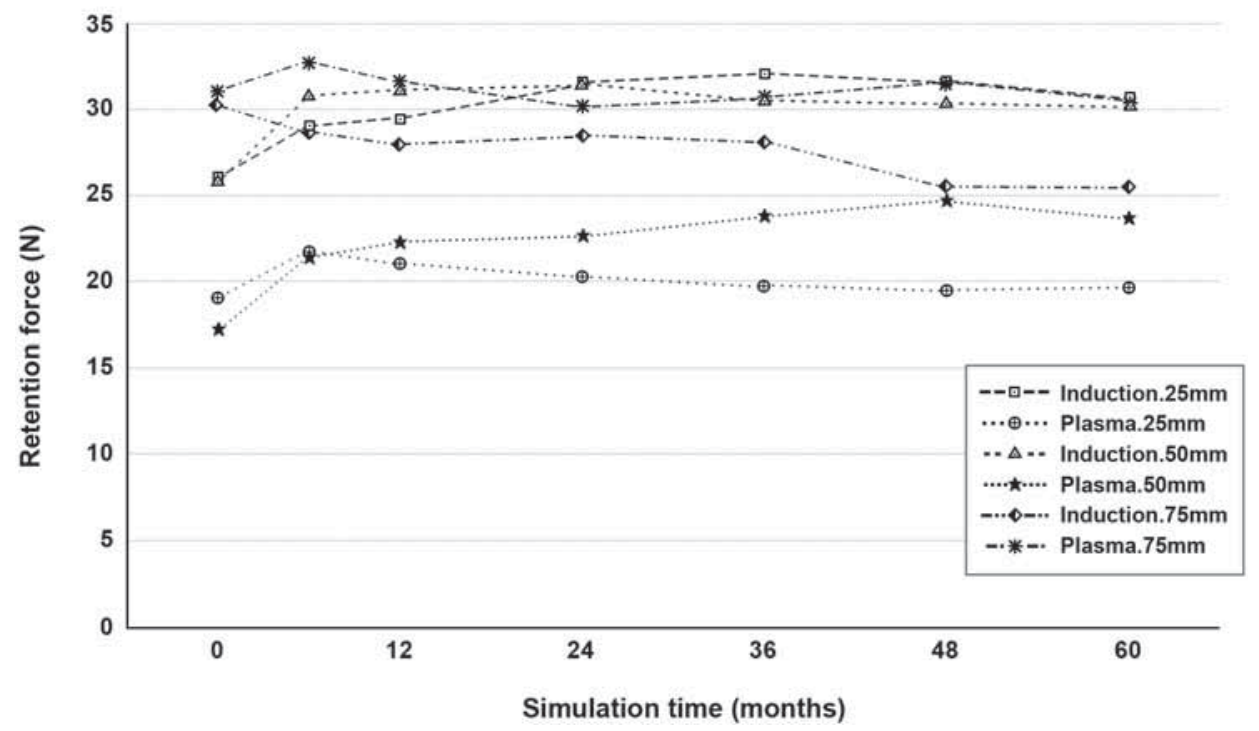

Figure 1- Retention force $(\mathrm{N})$ of Co-Cr metallic frameworks for undercut $(\mathrm{mm}) \times$ casting method (induction/centrifugation or plasma/vacuum-pressure) $x$ time of insertion/removal simulation (months) 


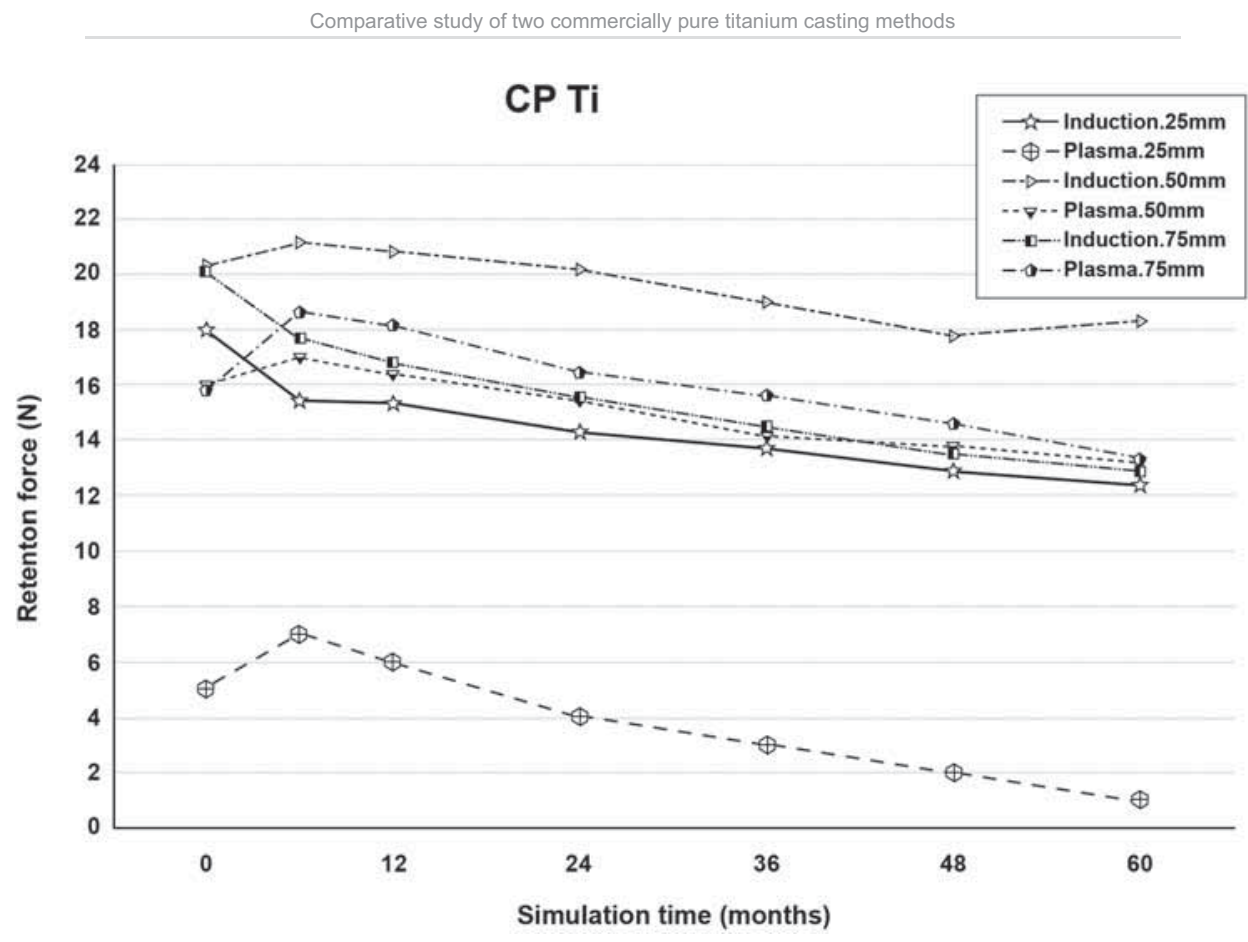

Figure 2- Retention force $(\mathrm{N})$ of $\mathrm{CP}$ Ti metallic frameworks for undercut $(\mathrm{mm}) \mathrm{x}$ casting method (induction/centrifugation or plasma/vacuum-pressure) $\mathrm{x}$ time of insertion/removal simulation (months)

showed uneven values (Figure 1), and induction casted frameworks always showed greater force values compared to those of plasma casted frameworks, except for the $0.75-\mathrm{mm}$ undercut. For CP Ti frameworks, more homogeneous values were observed over time, with force tending to decrease throughout the test (Figure 2).

\section{DISCUSSION}

Since the first studies on $\mathrm{CP} \mathrm{Ti}$ use in prosthodontics in the early 1980's, numerous equipments and materials have been designed to make $\mathrm{CP} \mathrm{Ti}$ an alternative to conventional alloys. Despite its remarkable biocompatibility and its desirable physical and mechanical properties, difficulties in casting still pose limits to its use $^{1,10,14,18,22}$.

Porosities in $\mathrm{CP} \mathrm{Ti}$ castings are the most frequently reported defects ${ }^{6,7,9,23,25}$, and they are easily detected by conventional dental radiographs. Several factors can lead to porosities in $\mathrm{CP} \mathrm{Ti}$ castings, such as: pressure difference between fusion and mold chambers, gas diffusion into the mold chamber during plasma casting, investment material permeability, reactivity between titanium and the investment material, and the significant difference between casting and mold temperatures, causing rapid solidification of the metal and lessening the likelihood of gas escape?

The low density of $\mathrm{CP} \mathrm{Ti}$ allowed for easy identification of porosities. Nonetheless, no defects were identified in $\mathrm{Co}-\mathrm{Cr}$ alloy specimens, possibly due to the fact that the $70 \mathrm{kV}$ tension was not sufficient. Therefore, these alloys require the use of medical or industrial devices with higher tension ${ }^{12}$.
In the present study, the casting pressure used in the vacuum-pressure machine (Discovery Plasma), according to the manufacturer, is 1471.12 torr. This pressure may possibly have caused the great number of porosities when this method is used, since the higher the injection pressure, the higher the liquid metal turbulence, leading to greater gas incorporation. Such porosities may occur also due to gas incorporation during the casting process. In this process, argon passes from the casting chamber to the mold chamber and thus incorporates into the material, producing porosities. The difference between casting and mold temperatures causes rapid solidification and cooling of the metal, which does not allow enough time for gases to escape ${ }^{9}$.

A possible reason why centrifugation castings produced fewer porosities is that argon can escape more rapidly due to the great centrifuge force, which is $40-60$ times greater than the force produced by pressure difference ${ }^{23}$.

In addition, it must be considered that the radiographic detection of porosities is recommended for casting quality control, but three-dimensional defects are represented in two dimensions. Thus, the use of a scale could provide information about how deep is the defect, as done in the present study $6,7,9,23,25$.

Porosities represent problems in the castings because there is a reduction in framework thickness, an especially important aspect for RPD frameworks since voids reduce metal cross-section and cause stress concentration, increasing the risk to fracture.

In the present study, $\mathrm{Co}-\mathrm{Cr}$ specimens were subject to standardized electrolytic polishing 
and $\mathrm{CP}$ Ti specimens, to a standardized chemical polishing. These procedures were elected in order to avoid the variation that mechanical polishing could generate. The superficial porosities could be exposed by any of these procedures, and care must be taken to evaluate the final state of each framework. As all the frameworks were previously evaluated radiographically, no defects were exposed by polishing, and none of the frameworks were rejected after polishing.

One of properties of titanium that has created interest for RPDs is its low modulus of elasticity, which allows for the positioning of clasps in more cervical and thus more esthetic areas, without producing excessive loads on abutment teeth ${ }^{3,11,14,17}$.

In the present study, CP Ti clasps with undercuts of $0.50 \mathrm{~mm}$ and $0.75 \mathrm{~mm}$ had a retentive force similar to that of plasma cast $\mathrm{Co}-\mathrm{Cr}$ clasps with undercuts of $0.25 \mathrm{~mm}$ and $0.50 \mathrm{~mm}$, respectively. These findings corroborate results reported by other authors ${ }^{3,14}$. Co-Cr clasps casted by induction showed greater retentive force throughout the study, thus presenting greater rigidity than plasma casted frameworks. Comparing $\mathrm{CP} \mathrm{Ti}$ and $\mathrm{Co}-\mathrm{Cr}$ clasps for the same undercuts, it was observed that $\mathrm{CP}$ Ti clasps always showed smaller retentive force, but more homogeneous values throughout the test. On the other hand, $\mathrm{Co}-\mathrm{Cr}$ clasps showed higher levels of retentive force and higher force variation throughout the insertion/removal simulation test.

Casting methods were compared for each undercut. For $\mathrm{Co}-\mathrm{Cr}$ specimens with undercut $0.25 \mathrm{~mm}$, it was observed that induction casted specimens had greater retentive force values than those casted by plasma. During the simulation test, induction casted frameworks showed a tendency to increase retentive force from the beginning toward the end of the test, whereas those casted by plasma had more homogeneous values. $\mathrm{CP} \mathrm{Ti}$ specimens had similar values for both methods, with a general tendency to reduce force values from beginning to end.

Regarding the $0.50 \mathrm{~mm}$ undercut, induction cast $\mathrm{Co}-\mathrm{Cr}$ specimens also had greater retentive force compared to plasma casted specimens. Yet, both methods showed a general tendency to increase values throughout the simulation test. CP Ti specimens showed no significant differences in retentive forces for induction casted specimens when compared to those casted by plasma, despite greater values for induction casted clasps. CP Ti showed a general tendency to reduce force from beginning to end.

Only the $0.75 \mathrm{~mm}$ experimental condition allowed for the detection of permanent deformation in some of tested clasps, demonstrated by complete lost of retention throughout the simulation test. For $\mathrm{Co}-\mathrm{Cr}$ clasps, induction casted specimens had an evident loss of retentive force, probably due to greater initial rigidity, whereas those casted by plasma showed more homogeneous values throughout the test. CP Ti clasps showed a reduction in retentive force values throughout the simulation test, for both casting methods.

Concerning clasp retentive force, it was observed that frameworks casted by induction and centrifugation showed greater rigidity throughout the insertion/removal simulation test. These data are especially important considering Co$\mathrm{Cr}$ clasps, since the smaller rigidity observed in plasma castings could provide the advantage of transmitting less load to the abutment tooth. Thus, based on these results, it is suggested that clasps casted by plasma/vacuum-pressure are more suitable. However, it must be taken into consideration the fact that these specimens had smaller retentive force, which could compromise clinical behavior. Confirmatory clinical studies are needed to ensure this possibility.

Comparing clasps with the same undercut, it was observed that $\mathrm{CP}$ Ti clasps always showed smaller retentive force and more uniform force values throughout the test, whereas $\mathrm{Co}-\mathrm{Cr}$ clasps showed greater force values and suffered greater variation. However, it must be considered the need for tests under different conditions than those used in the present study. For instance, tests in wet environments, non-rigid system with periodontal ligament simulation could allow for better evaluation of the retentive capacity in metallic frameworks.

Based on these observations, it is evident that there is a need to evaluate various aspects before CP Ti can become a material of choice in the fabrication of RPD metallic frameworks. Hence, Co$\mathrm{Cr}$ alloys remain the ideal material.

\section{CONCLUSIONS}

Within the limitations of the present study and based on the obtained results, it is possible to conclude that:

Casting methods interfere with the properties of the studied materials (CP Ti and Co-Cr alloy);

$\mathrm{CP} \mathrm{Ti}$ specimens cast by plasma/vacuumpressure showed more porosities than those casted by induction/centrifugation. For Co- $\mathrm{Cr}$ castings, the occurrence of porosities could not be observed with either casting method;

Specimens cast by plasma/vacuum-pressure showed greater flexibility and those casted by induction/centrifugation showed greater rigidity. Consequently, retentive forces were generally greater for induction/centrifugation casted specimens than for those obtained by plasma/ vacuum-pressure.

\section{ACKNOWLEDGEMENTS}

This study was supported by the State of São Paulo Research Foundation (FAPESP), grant \#98/13868-9 


\section{REFERENCES}

1- Baltag I, Watanabe K, Miyakava O. Internal porosity of cast titanium removable partial dentures: influence of sprue direction and diameter on porosity in simplified circumferential clasps. Dent Mater. 2005;21:530-7.

2- Blackman R, Barghi N, Tran C. Dimensional changes in casting titanium removable partial dentures frameworks. J Prosthet Dent. 1991;65:309-15

3- Bridgeman JT, Marker VA, Hummel SK, Benson BW, Pace LL. Comparison of titanium and cobalt-chromium removable partial denture clasps. J Prosthet Dent. 1997;78:187-93.

4- Cecconi BT, Koeppen RG, Phoenix RD, Cecconi ML. Casting titanium partial denture frameworks: a radiographic evaluation. J Prosthet Dent. 2002;87:277-80.

5- Chai TI, Stein RS. Porosity and accuracy of multiple-unit titanium castings. J Prosthet Dent. 1995;73:534-41.

6 - Eisenburger M, Addy M. Radiological examination of dental castings - a review of the method and comparisons of the equipment. J Oral Rehabil. 2002;29:609-14.

7- Eliopoulos D, Zinelis S, Papadopoulos T. Porosity of cpTi casting with four different casting machines. J Prosthet Dent. 2004:92:377-81.

8- Guilin Y, Nan L, Yousheng L, Yining W. The effects of different types of investments on the alpha-case layer of titanium castings. Prosthet Dent. 2007;97:157-64.

9- Herø $H$, Syverud $M$, Waarli $M$. Mold filling and porosity in castings of titanium. Dent Mater. 1993;9:15-8.

10- Hruska AR, Borelli P. Quality criteria for pure titanium casting, laboratory soldering, intraoral welding, and a device to aid in making uncontaminated castings. J Prosthet Dent. 1991;66:5615.

11- Jang KS, Youn SJ, Kim YS. Comparison of castability and surface roughness of commercially pure titanium and cobaltchromium denture frameworks. J Prosthet Dent. 2001;86:93-8. 12- Kim D, Park C, Yi Y, Cho L. Comparison of cast Ti-Ni alloy clasp retention with conventional removable partial denture clasps. J Prosthet Dent. 2004;91:374-82.
13- Kotake M, Wakabayashi N, Ai M, Yoneyama T, Hamanaka $\mathrm{H}$. Fatigue resistance of titanium-nickel alloy cast clasps. Int J Prosthodont. 1997; 10:547-52

14- Lautenschlager EP, Monaghan P. Titanium and titanium alloys as dental materials. Int Dent J. 1993;43:245-53.

15- Rodrigues RC, Macedo AP, Torres EM, Mattos MG, Ribeiro RF. Retention force of T-bar clasps for titanium and cobalt-chromium removable partial dentures. Braz Dent J. 2008;19:209-13.

16- Rodrigues RC, Ribeiro RF, Mattos MG, Bezzon OL. Comparative study of circumferential clasp retention force for titanium and cobalt-chromium removable partial dentures. J Prosthet Dent. 2002;88:290-6.

17- Shimpo H. Effect of arm design and chemical polishing on retentive force of cast titanium alloy clasps. J Prosthodont. 2008; 17:300-7.

18- Sunnerkrantz PA, Syverud $M$, Herö $H$. Effect of casting atmosphere on the quality of Ti-crowns. Scand J Dent Res. 1990;98:268-72.

19- Takahashi J, Zhang JZ, Okazaki M. Effect of casting methods on castability of pure titanium. Dent Mater J. 1993;12:245-52.

20- Vallittu PK, Kokkonen M. Deflection fatigue of cobaltchromium, titanium, and gold alloy cast denture clasp. J Prosthet Dent. $1995 ; 74: 412-9$.

21- Wang RR, Boyle AM. A simple method for inspection of porosity in titanium casting. J Prosthet Dent. 1993;70:275-6.

22- Wang RR, Fenton A. Titanium for prosthodontic applications: a review of the literature. Quintessence Int. 1996;27:401-8.

23- Watanabe I, Woldu M, Watanabe K, Okabe T. Effect of casting method on castability of titanium and dental alloys. J Mater Sci Mater Med. 2000;11:547-53.

24- Watanabe K, Miyakawa O, Takada Y, Okuno O, Okabe T. Casting behavior of titanium alloys in a centrifugal casting machine. Biomaterials. 2003;24:1737-43.

25- Zinelis S, Tsetsekou A, Papadopoulos T. Thermal expansion and microstructural analysis of experimental metal-ceramic titanium alloys. J Prosthet Dent. 2003;90:332-8. 